\title{
Design and Performance Analysis of a Rectangular Microstrip Line Feed Ultra-Wide Band Antenna
}

\author{
Ranjan Mishra $^{1}$, Jeevani Jayasinghe ${ }^{2}$, Raj Gaurav Mishra ${ }^{1}$ and Piyush Kuchhal ${ }^{1}$ \\ ${ }^{1}$ College of Engineering Studies, University of Petroleum and Energy Studies, \\ Dehradun, India \\ ${ }^{2}$ Wayamba University of Sri Lanka, Sri Lanka.3 \\ rmishra@ddn.upes.ac.in, jeevani@wyb.ac.lk,rgmishra@ddn.upes.ac.in, \\ pkuchhal@ddn.upes.ac.in
}

\begin{abstract}
The research article presents the design and performance of a planar microstrip-line feed monopole antenna for Ultra-Wide band $(U W B)$ frequency. The proposed antenna is consisting of a rectangular patch antenna loaded with a rectangular slot on its center position. The antenna is etched over a FR4 epoxy substrate with a dimension of $30 \mathrm{~mm}$ by $26 \mathrm{~mm}$ by $1.52 \mathrm{~mm}$. The simulated and experimental results are compared and analysis showed a good proximity. The measured and simulated results confirm that the design covers the entire region of $U W B$ range $(4.1 \mathrm{GHz}$ to $8.8 \mathrm{GHz})$. The measurement indicates that the designed antenna is a good candidate in terms of return loss, VSWR, radiation efficiency for UWB application.
\end{abstract}

Keywords: UWB, slot, notch, return loss, impedance

\section{Introduction}

The Federal Communications Commission (FCC) in 2002 passes the recommendation of Ultra-Wide Band (UWB) in the frequency range of 3.1 to $10.6 \mathrm{GHz}$. [1]. This approval motivated the research and industrial society for the development of antennas suitable to operate in this band. From impulse to pulse radio, the UWB technology gives a new insight for the spread of wireless communication system. Antenna is one of the chief components of the wireless system. Low cost and compact antennas are the need of the hour for various wireless applications in UWB applications [2]. The compact quality of microstrip patch antenna in weight and size, fit well in to device and its property set it as a good candidate for the development UWB antenna. [3]. Though the microstrip antenna shows a drawback in terms of narrow bandwidth, but many techniques have been introduced into research area that tends to increase its bandwidth. Some of these include square-ring slot on patch [4], meandered ground plane [5], integrated bandpass filter [6], ring shaped [7], and double printed U shaped [8]. Several other designs of the planar UWB antenna have been proposed other various literatures. These include the designs at the specific frequency [9] and design to enhance the bandwidth [10]. However, some of them involve complex calculations. Recently many literature introduces the concept of notch to get the desired result in monopole antenna [11-12] and also UWB in WiMAX application [13].

In the present study, a simple design of a rectangular patch microstrip antenna with one slot and four notches at the corner is presented. This antenna is centrally loaded with a rectangular slot and feed with the microstrip line. The $-10 \mathrm{~dB}$ bandwidth of the antenna covers $3.8 \mathrm{GHz}$ to $9 \mathrm{GHz}$ of the UWB band. The outline of this paper is as follows. In the section 2 , the dimension and geometry of the proposed antenna is presented. The analysis of the simulation and experimental results are done in Section 3. The comparison with the 
theoretical and measured impedance using transmission line analysis is in Section 4, whereas the conclusion is finalized in Section 5.

\section{Antenna Geometry}

Figure 1 shows the planer geometry of the antenna. It comprises of a rectangular patch of length (L) and width (W). The rectangular slot of length (Ls) and width (Ws) is etched at the center and on the front side of the patch. The microstrip feed line of dimension Lm and $\mathrm{Wm}$ is connected with the 50 -ohm source. The partial ground plane of length (LG) is on the back side of the substrate.

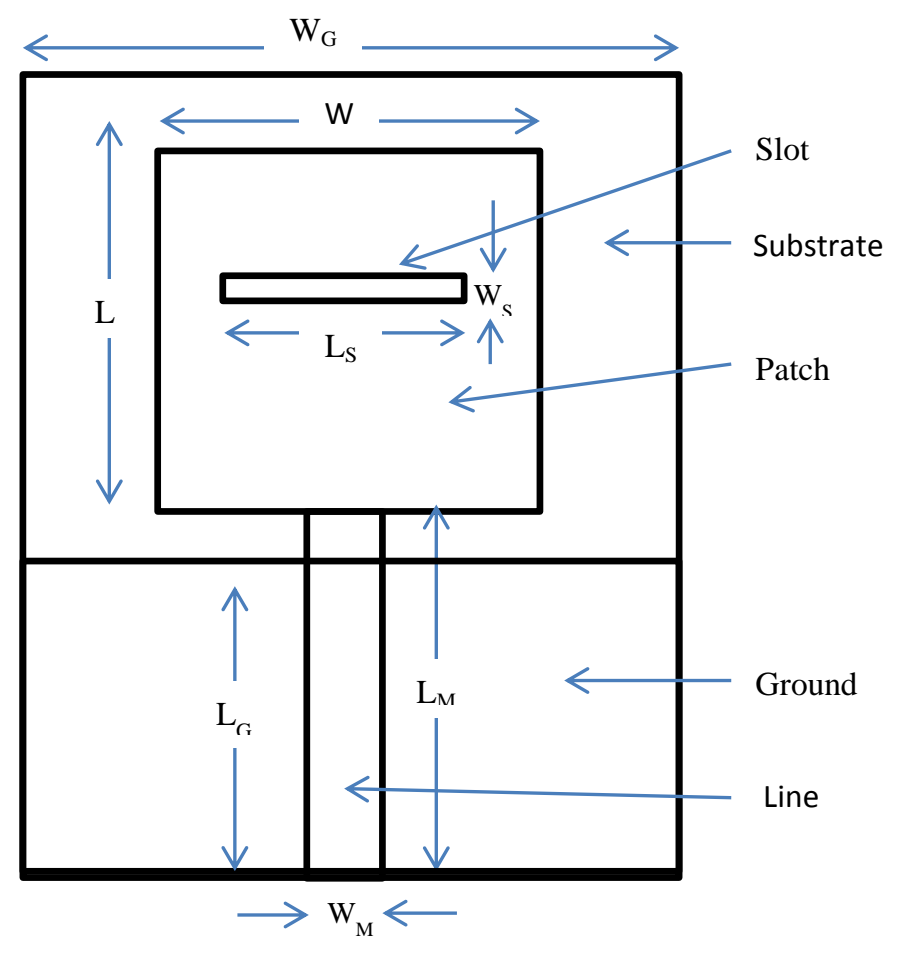

Figure 1. The Plane Geometry of the Proposed Antenna

The dimension the patch can be found by using simple equations [14]. The dimension of the slot is calculated by slot line analysis [15]. The equation reflects that the dimensions are related to dielectric constant of the substrate as well as and the operating frequency. The center frequency ' $\mathrm{f}$ ' for the entire dimension in the above equations simulations is taken to be $6 \mathrm{GHz}$. These dimensions present the idea for the starting point for the present design of the UWB antenna. Optimization in simulation is done on length and width of the patch over the dimension obtained by the equations. The final dimension is taken to get the best result and ease of fabrication. The final design simulation is done using optimization of the dimension to get the best result. The ground plane of the antenna is of the same width as that of substrate.

All dimension of the antenna is tabulated in Table 1. The substrate material for the fabrication is epoxy FR4 epoxy having a dielectric constant of 4.4 and loss tangent of 0.01 . The height of the substrate is taken as $1.6 \mathrm{~mm}$. Copper is used as the conducting material for patch and ground. 
Table 1. Dimension of the Antenna

\begin{tabular}{|l|l|}
\hline Length of the Patch & $14 \mathrm{~mm}$ \\
\hline Width of the Patch & $16 \mathrm{~mm}$ \\
\hline Length of Microstrip line & $12 \mathrm{~mm}$ \\
\hline Width of Microstrip line & $3.8 \mathrm{~mm}$ \\
\hline Length of slot & $9 \mathrm{~mm}$ \\
\hline Width of slot & $1 \mathrm{~mm}$ \\
\hline Length of Ground plane & $11 \mathrm{~mm}$ \\
\hline Length of Notch & $0.5 \mathrm{~mm}$ \\
\hline Width of Notch & $2 \mathrm{~mm}$ \\
\hline
\end{tabular}

\section{Simulation \& Experimental Results}

The simulation is done on HFSS antenna design software. The various dimensions are taken from the result mentioned in Table 1. The best performance is obtained with centrally placed slot. It is observed from the HFSS result that the UWB performance has been obtained, since the proposed antenna resonates from $3.3 \mathrm{GHz}$ to $9.7 \mathrm{GHz}$. In the next step, the proposed antenna is fabricated on epoxy FR4 substrate by mechanical and chemical etching method. The front and back side of the antenna is shown in Figure 2.
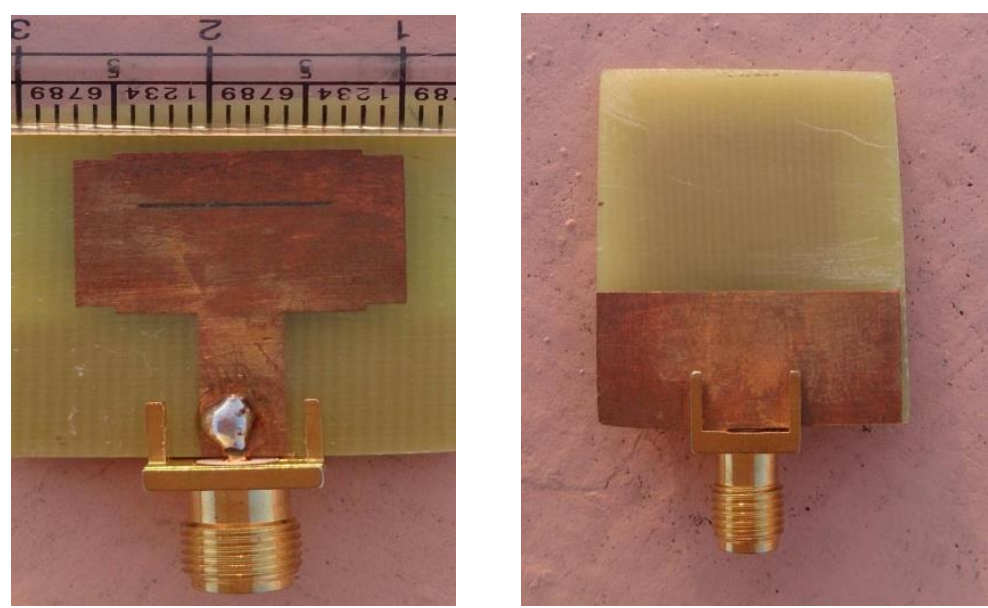

Figure 2. The Front and Back Side of the Fabricated Antenna

To validate the result, the characterization testing of the antenna is done on vector network analyzer. The measured values of the return loss at different frequencies ranging from $3 \mathrm{GHz}$ to $11 \mathrm{GHz}$ are recorded and it is plotted against the simulated value. The plot of the return loss at UWB frequency range of the two values (measured and simulated) is shown in Figure 3. 


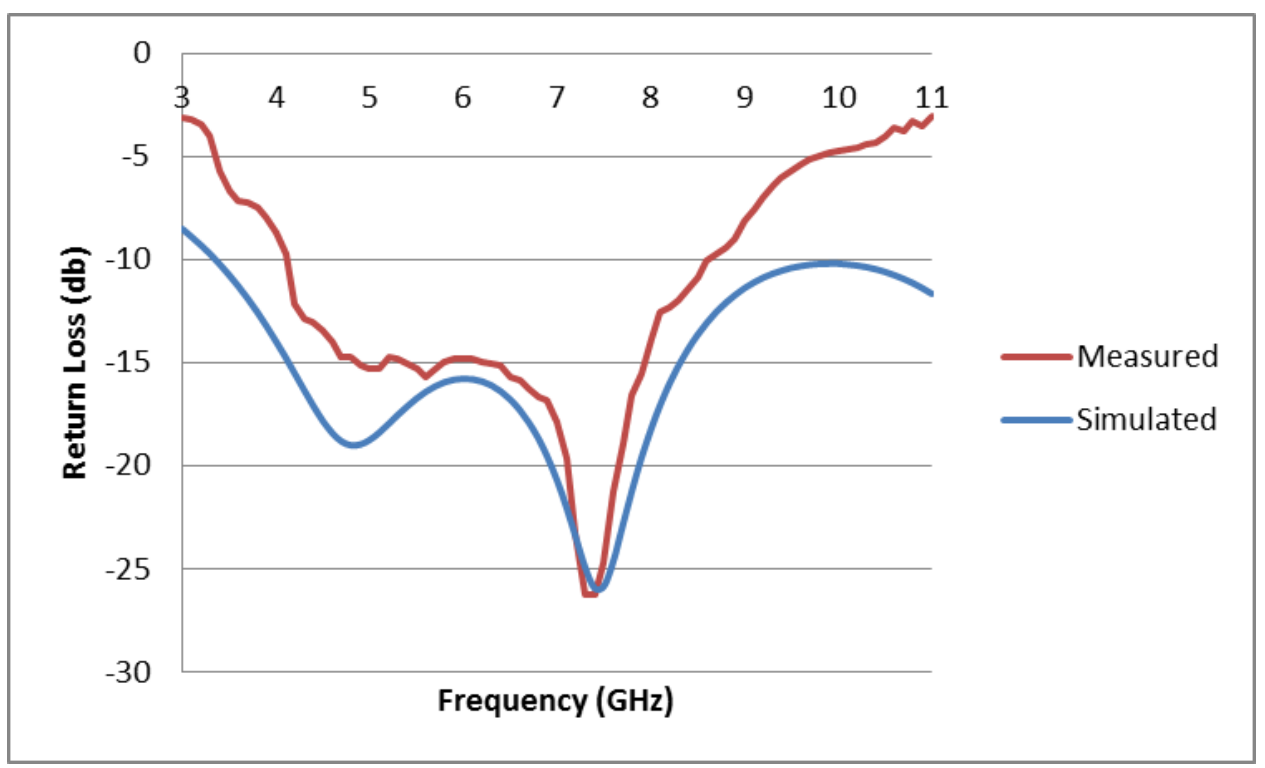

Figure 3. Return Loss of the Simulated And Measured Antenna

It is evident from the Figure 3, that the measured results are close to the simulated result. In the simulation the antenna covers the range from $3.3 \mathrm{GHz}$ to $9.7 \mathrm{GHz}$ with two peak value of return loss. One is $-25.85 \mathrm{~dB}$ at $7.5 \mathrm{GHz}$ and another at $4.8 \mathrm{GHz}$ with a return loss of $-19.17 \mathrm{~dB}$. The measured value cover the UWB range and has a $-10 \mathrm{~dB}$ band coverage from $4.1 \mathrm{GHz}$ to $8.8 \mathrm{GHz}$. it ha sthe maximum peak at $7.4 \mathrm{GHz}$ with a return loss of $-25.94 \mathrm{~dB}$. The peak return loss and frequency of the simulated and measured are almost close. The result pattern of the measured is very much same as that of the simulation results.

The measurement of the VSWR of the fabricated antenna is plotted along with the results obtained in the simulation and the plot is shown in Figure 4. The VSWR is showing a good result $(\leq 2)$ in the UWB range as per the specification of FCC. Over a region of $4.1 \mathrm{GHz}$ to $8.8 \mathrm{GHz}$ the VSWR is in between 1 and 2. The best value of VSWR is obtained as 1.12 at $7.5 \mathrm{GHz}$.

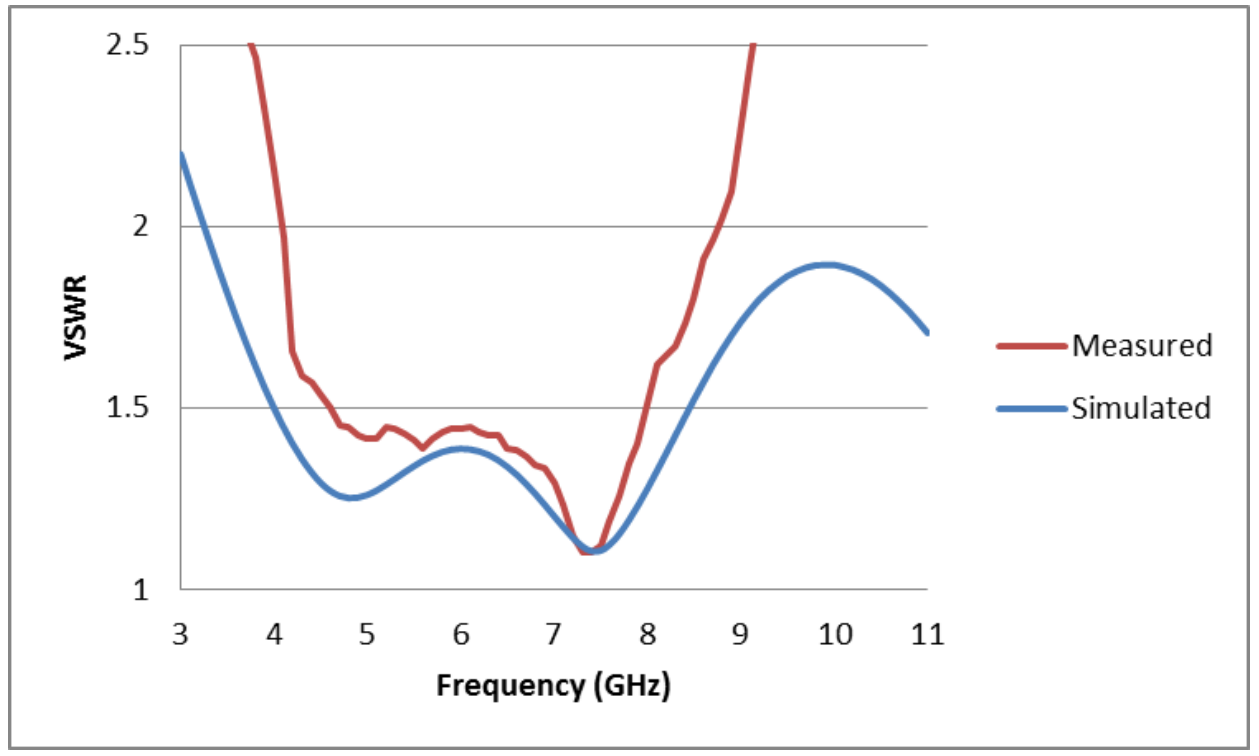

Figure 4. VSWR of the Simulated and Measured Antenna 
It has been observed from the Figure 3 and 4 that the good result in the UWB band is obtained as the antenna resonates fairly in the entire UWB region. The pattern and peak values of both the simulated and measured result are same. This justifies a good validation of the result.

The plot of radiation efficiency is shown in Figure 5. The radiation efficiency lie in between $82 \%$ to $94 \%$ throughout the UWB range. This indicates that the directivity and gain of the antenna is nearly very close to each other.

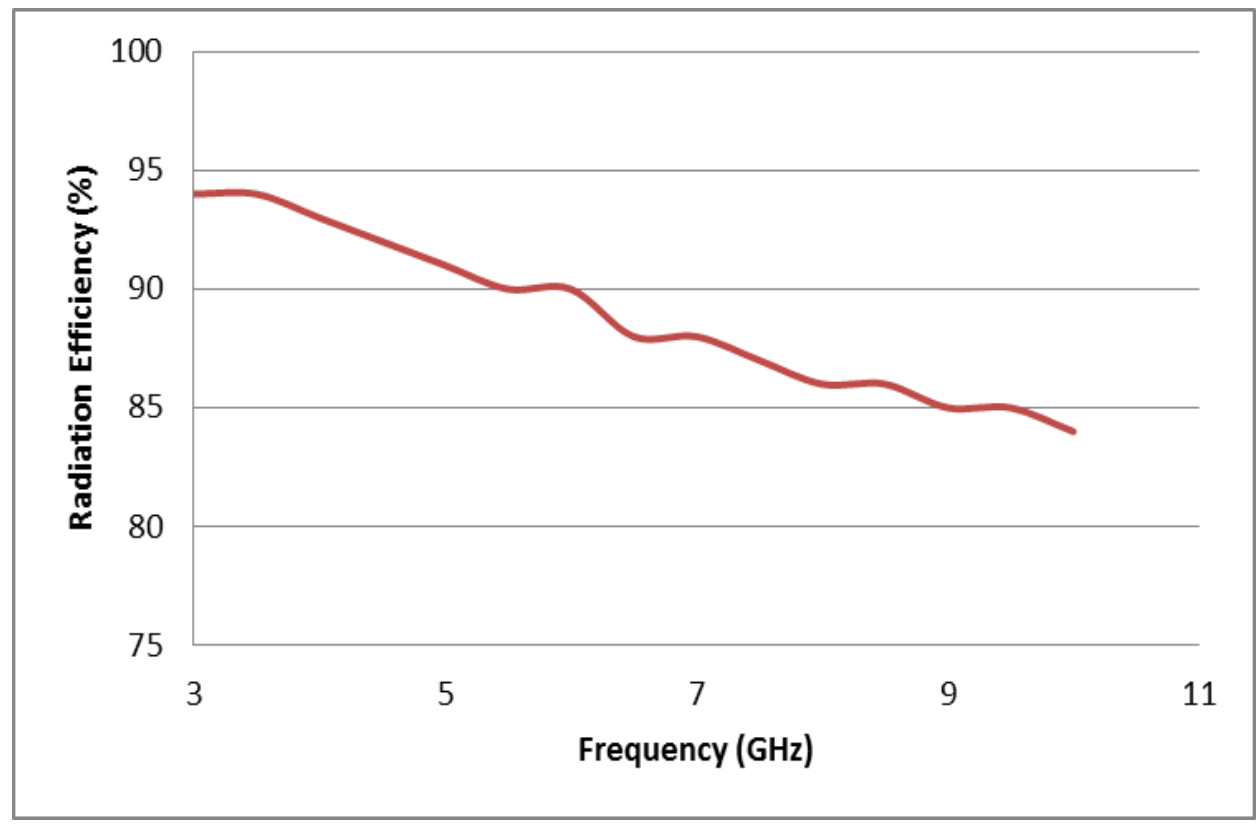

Figure 5. Radiation Efficiency of the Antenna

The current path of the proposed patch antenna is shown in Figure 6. It is observed that the current path is elongated and longer than a plain rectangular antenna. The insertion of the proper slot gives more current density and hence enhances the bandwidth.

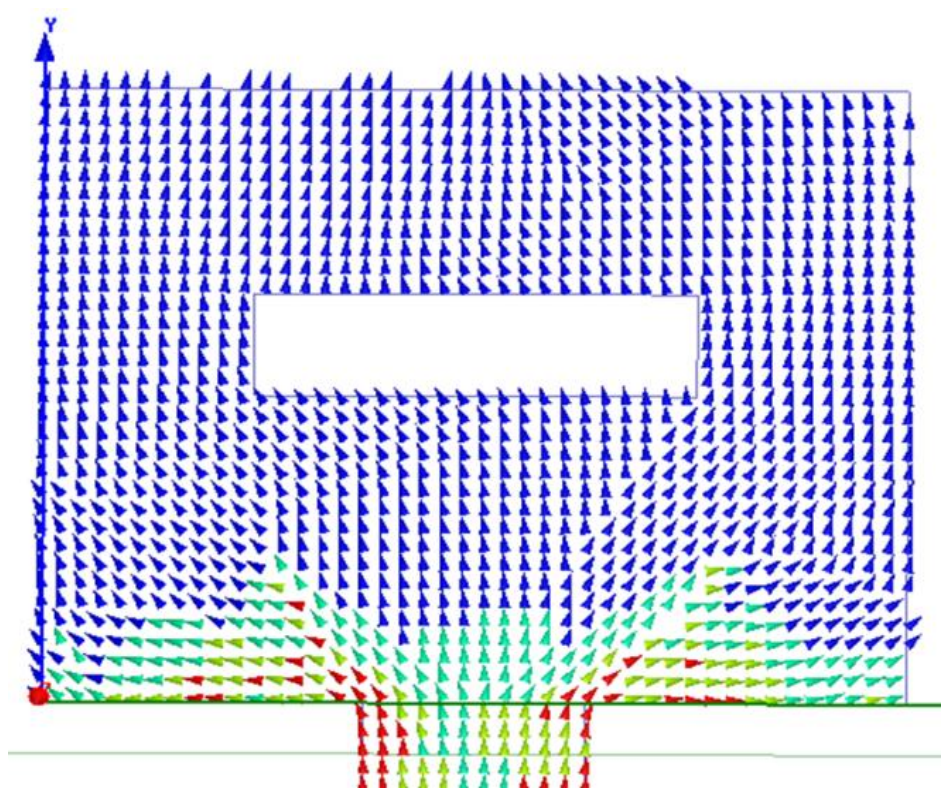

Figure 6. Current Path of the Patch 


\section{Impedance Calculation}

The impedance of the antenna is calculated using transmission line model. The rectangular patch is represented as a parallel-plate transmission line connecting two radiating slots, each of width $\mathrm{W}$ and height $\mathrm{h}$. this model provides a relatively fair physical insight into the behavior of the patch antenna.

The general representation of a 3-port transmission line [14] of the microstrip antenna is shown in Figure 7.

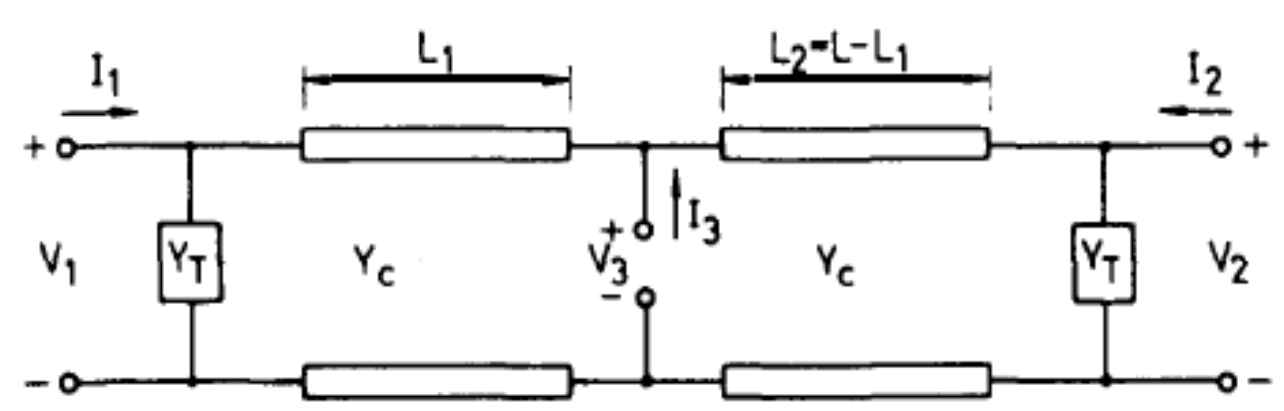

Figure 7. A 3-Port Equivalent Circuit of the Antenna

The admittance matrix of 3-port circuit is given as:

$$
[Y]=\left[\begin{array}{ccc}
Y_{S}+Y_{c} \operatorname{coth}\left(\gamma L_{1}\right) & -Y_{m} & -Y_{c} \operatorname{csch}\left(\gamma L_{1}\right) \\
-Y_{m} & Y_{S}+Y_{c} \operatorname{coth}\left(\gamma L_{2}\right) & -Y_{c} \operatorname{csch}\left(\gamma L_{2}\right) \\
-Y_{c} \operatorname{csch}\left(\gamma L_{1}\right) & -Y_{c} \operatorname{csch}\left(\gamma L_{2}\right) & Y_{c} \operatorname{coth}\left(\gamma L_{1}\right)+Y_{c} \operatorname{coth}\left(\gamma L_{2}\right)
\end{array}\right]-
$$

Here $Y_{c}$ is the characteristic admittance of the microstrip line formed by the patch.

$$
\begin{gathered}
\gamma=\alpha+j \beta \text { is the complex propagation constant of the line. } \\
\alpha=0.5 \beta \tan \delta \text {. Here tan } \delta \text { is the loss tangent of the substrate. } \\
\beta=k_{0} \sqrt{\varepsilon_{\text {eff }}}, k_{0}=2 \pi / \lambda_{0}=\text { free space wave number. }
\end{gathered}
$$

Here $Y_{c}$ is the characteristic admittance of the microstrip line formed by the patch antenna, and $Z_{c}=1 / Y_{c}$, is the characteristic impedance.

In the case of microstrip line feed antenna, $I_{1}=I_{2}=0$ and $L_{1}=0$. Therefore from equation (1), the value of the antenna input admittance is given as:

$Y_{\text {in }}=\frac{Y_{c}^{2}+Y_{S}^{2}-Y_{m}^{2}+2 Y_{S} Y_{c} \operatorname{coth}(\gamma L)-2 Y_{m} Y_{c} \operatorname{cshh}(\gamma L)}{Y_{S}+Y_{c} \operatorname{coth}(\gamma L)}$

Taking into account the parasitic effect of the feed line,

$Y_{i n}=\left(1-\frac{W_{m}}{W}\right) Y_{s}+\frac{Y_{C}^{2}-Y_{m}^{2}+2 Y_{S} Y_{C} \operatorname{coth}(\gamma L)-2 Y_{m} Y_{C} \operatorname{cshh}(\gamma L)}{Y_{S}+Y_{C} \operatorname{coth}(\gamma L)}$

The value of self-admittance of slots $(Y s)$ and mutual admittance $(Y m)$ are governed by the following set of equations.

The self-admittance, $Y_{s}=G_{s}+j B_{s}$

$G_{s}=\frac{1}{\pi^{2} n_{0}} \cdot\left\{\left(w \operatorname{Si}(w)+\frac{\sin w}{w}+\cos w-2\right)\left(1-\frac{s^{2}}{24}\right)+\frac{s^{2}}{12}\left(\frac{1}{3}+\frac{\cos w}{w^{2}}-\frac{\sin w}{w^{3}}\right)\right\}$

$\Delta L=0.412 h \frac{\left(\varepsilon_{e f f}+0.3\right)\left(\frac{W}{h}+0.264\right)}{\left(\varepsilon_{e f f}-0.258\right)\left(\frac{W}{h}+0.8\right)}$

The mutual admittance, $Y m=G_{m}+j B_{m}$ for rectangular microstrip antenna.

Here, $G_{m}=K_{g} F_{g} G_{s}$ 
Putting the value of equations 4,5 and 6 in equation 2, the value of line parameter $\left(Y_{c}\right)$ is obtained. The line parameter is connected with the input admittance. A generalized solution of this equation is given as:

$Z_{\text {in }}=Z_{c}\left|\frac{Y_{C}+j Y_{L} \tan (\beta L)}{Y_{L}+j Y_{c} \tan (\beta L)}\right|$

For a normalized value of $\beta L=\pi, Z_{i n}=Z_{L}$. That means both the line impedance and the input impedance are of the same value at this extreme case of optimization.

Solving equation 2 and putting the different value from equation, the normalized value of the characteristic impedance, in terms of the antenna dimension and dielectric constant of the substrate is given as:

$$
Z_{c}=\frac{120 \pi / \sqrt{\varepsilon_{\text {eff }}}}{\frac{W}{h}+1.393+0.667 \ln \left(\frac{W}{h}+1.444\right)}
$$

A plot of characteristic impedance from the theoretical analysis (wave guide model) and the transmission line method is shown in the Figure 8 for various value of width of the patch. A close proximity of the two values is observed. Though the transmission line method is not so accurate, but it gives a simple approach.

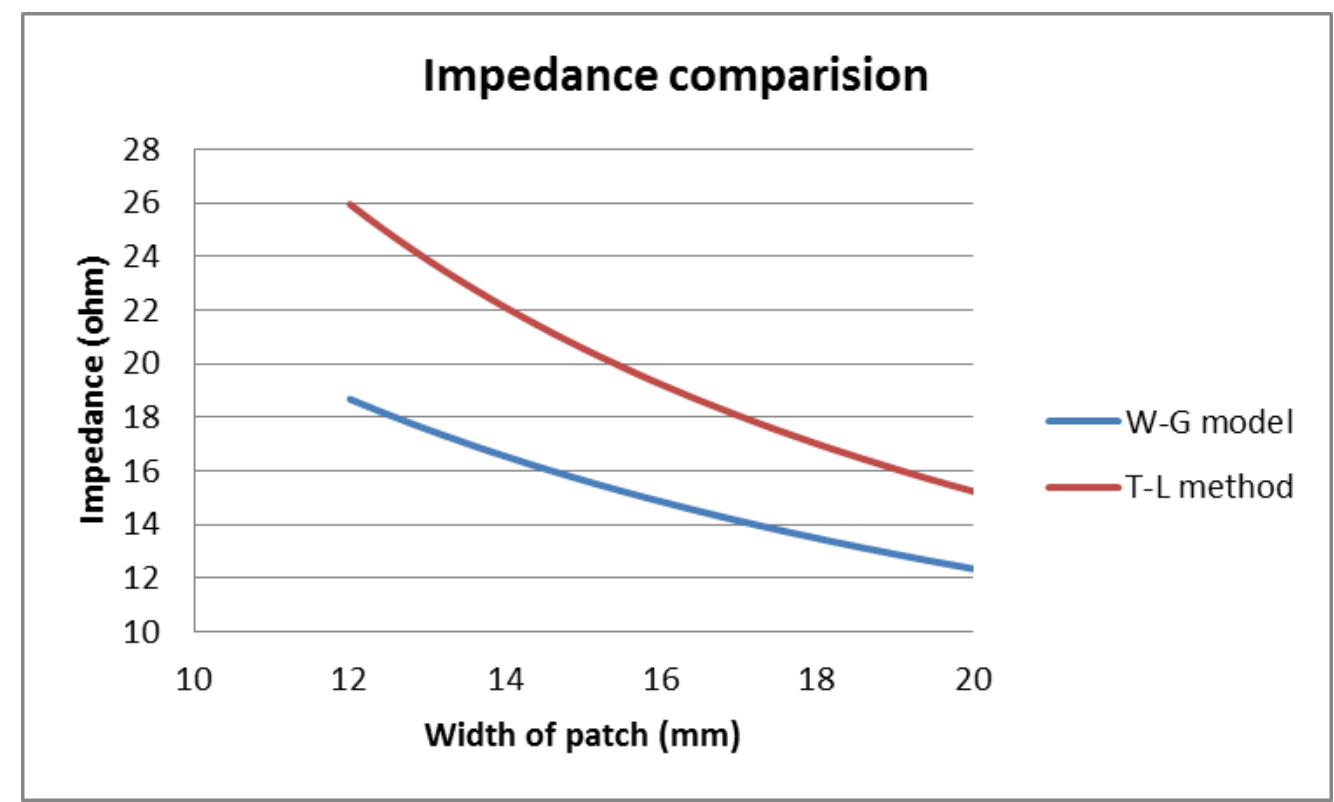

Figure 8. Impedance Plot of the Theory and Measured Value in UWB Region

\section{Conclusion and Discussion}

A simple monopole microstrip antenna is proposed and a prototype is fabricated. The antenna shows a good coverage in the ultra-wide band region. Also the measurement result shows a good agreement with the simulated one. The antenna exhibited a stable radiation patterns. Due to its wide bandwidth, the antenna can be considered as a potential candidate for cost effective UWB applications.

\section{References}

[1] FCC, First report and order on ultra-wideband technology, Technical Report, (2002).

[2] G. Z. Rafi and L. Shafai, "Wideband V-Slotted Diamond- Shaped Microstrip Patch Antenna,"Electronics Letters, vol. 40, no. 19, (2004), pp. 1166 -1167. 
[3] Y. Zehforoosh, C. Ghobadi and J. Nourinia, "Antenna design for Ultra - Wideband Application Using a New Multilayer Structure,” Progress in Electromagnetics Research Symposium Beijing, March (2007), pp. 26-30.

[4] S. Sadat, M. Fardis, F. Geran and G. Dadashzadeh, "A compact microstrip square-ring slot antenna for UWB applications," Progress In Electromagnetics Research, vol. 67, (2007), pp 173-179.

[5] J. S. Kuo and K. L. Wong, "A Compact Microstrip Antenna with Meandering Slots in the Ground Plane," Microwave and Optical Technology Letters, vol. 29, no. 2, (2001), pp. 95-97.

[6] M. H. Badjian, C. K. Chakrabarty, C. H. Goh and S. Devkumar, "An Impulse UWB Patch Antenna with Integrated Bandpass Filter," Proceedings of the 6th National Conference on Telecommunication Technologies and the 2th Malaysia Conference on Photonics, Putrajaya, (2007), pp. 26-28.

[7] M.Gopikrishna, D. D. Krishna, A. R. Chandran and C. K. Aanandan, "Square monopole antenna for ultra- wide band communication applications," Journal of Electromagnetic Waves and Applications, vol. 21, no. 11, (2007), pp 1525-1537.

[8] J. X. Xiao, X. X. Yang, G. P. Gao,and J. S. Zhang, "Double printed U-shape ultra-wideband dipole antenna," Journal of Electromagnetic Waves and Applications, vol. 22, no. 8-9, (2008), pp. 1148-1154.

[9] A. Foudazi, "A Small UWB Planar Monopole Antenna with Added GPS/GSM/WLAN Bands, IEEE transaction", vol 60, (2012), pp. 2987-2992.

[10] Z. Guo "Bandwidth Enhancement of Monopole UWB Antenna With New Slots and EBG Structures", IEEE antenna and wireless propagation letter, vol 12, (2013), pp. 1550-1553.

[11] P. S. Bakariya, S. Dwari and M. Sarkar, "Printed Ultra-wideband Monopole Antenna with Four Notch Band”, Wireless Personal Communications, vol. 84, no. 4, (2015), pp. 2989-2999.

[12] R. Kumar, V. P.Naidu, V. Kamble and R. V. S. R.-Krishna, "Simulation, Design of Compact Multi-band Microstrip Slot Antennas for WiMAX/WLAN and UWB Applications", Wireless Personal Communications, vol. 80, no. 3, (2015), pp 1175-1192.

[13] G. S. Rao, S. S. Kumar and R. Pillalamarri, "Cross shaped slot printed UWB monopole antenna with notch function”, Microsystem Technologies, vol. 21, no. 11, (2014) November, pp. 2327-2330.

[14] S. Jain, P. S. Tomar and G. S. Tomar, "Design \& Analysis of Proximity Fed Circular Disk Patch Antenna", International Journal of Emerging Technology and Advanced Engineering Volume 2, Issue 10, (2012) October, pp 126-131,

[15] C. Balanis, "Antenna Theory; Analysis and Design", 2nd edition Wiley and Sons, New York, (1982).

[16] K. C. Gupta, R. Garg, I. Bahl and P. Bhartia, "Microstrip Lines and Slotlines," 2nd edition, Artech House, (1996). 